\title{
Control of powdery mildew (Podosphaera leucotricha) on apple seedlings using anhydrous milk fat and soybean oil emulsions
}

\author{
K.V. Wurms and A. Ah Chee \\ The New Zealand Institute for Plant E Food Research Limited, Private Bag 3230, \\ Hamilton 3240, New Zealand \\ Corresponding author: Kirstin.Wurms@plantandfood.co.nz
}

\begin{abstract}
Powdery mildew (PM) is one of the most serious global diseases of apples, roses, cucurbits, grapes and cereals. The potential of anhydrous milk fat (AMF) and soybean oil (SBO) formulations to control apple PM (caused by Podosphaera leucotricha) on the apple cultivar 'Royal Gala' was investigated. Potted seedlings in a glasshouse were left unsprayed or subjected to weekly sprays of AMF, SBO, fungicide (sulphur as Kumulus ${ }^{\circledR}$ DF), or water. During 6-7 weeks of treatment the AMF and SBO formulations significantly reduced PM to $<12 \%$ infection of the leaf area compared with $100 \%$ in unsprayed and water control plants. There were no significant differences in PM control between AMF and the fungicide treatment, but $\mathrm{SBO}$ gave disease control equal to or exceeding the fungicide. After two experiments, plant height, weight and stem girth were significantly higher in plants treated with natural product formulations and the fungicide treatment than those in the unsprayed and water treatments.
\end{abstract}

Keywords anhydrous milk fat, soybean oil, powdery mildew, apple seedlings.

\section{INTRODUCTION}

Powdery mildew (PM) is one of the most important diseases worldwide of a range of key horticultural crops (Kumar et al. 1992; Agrios 1997). Apple powdery mildew, caused by Podosphaera leucotricha (Ell. and Ev.), is present in all apple-growing regions of the world, where it requires as many as 18 applications of fungicides for control in some countries (Yoder 1992). The ubiquitous disease creates considerable problems because it reduces the photosynthetic area of leaves in young non-bearing plants, which can severely stunt the growth of seedlings, and can diminish yield $(50-100 \%$ in the absence of control) in mature plants. Infections on fruit cause russeting, resulting in downgraded quality and value (Yoder 1992). Although the use of resistant cultivars offers effective control, breeding new cultivars is a long and laborious process. Where resistance genes are identified, there is the potential for new PM races to be selected that overcome the host resistance (Caffier \& Parisi 2007). For susceptible commercial varieties, there are several limitations with existing controls. Demethylation-inhibiting fungicide resistance has emerged (Creemers \& Vanmechelen 1999; Gao et al. 2009), and sulphur is a restricted product requiring approval from BioGro for use in New Zealand organic systems (BioGro 2011). There is also a lack of efficacious organic alternatives (Creemers et al. 2007), particularly 
those with eradicant activity. These limitations drive the need to find new control alternatives. Brazilian (Bettiol 1999) and Australian (Crisp \& Bruer 2001) researchers have reported that milk is as effective as conventional fungicides for the control of PM in squash and wine grapes, respectively. However, there have been problems associated with using raw milk as a soft fungicide, which include milk spoilage, development of unpleasant odours, difficulties in handling and storing large volumes, poor durability of control, and unwanted growth of other non-target organisms, such as sooty moulds. Different components in milk have been tested, and it was found that the fatty fraction was the most fungitoxic to powdery mildews (K.V. Wurms, unpublished data).

The anti-fungal activity of plant oils (olive oil, canola oil, corn oil, grape seed oil, peanut oil, safflower oil, soybean oil and sunflower oil) and mineral oils (e.g. JMS stylet-oil ${ }^{\oplus}$ ) against powdery mildew has also been reported (Kabara 1978, 1984; Ko et al. 2003). Issues with fungicides containing fats or plant oils include expense, blockage of agricultural spray equipment, variable disease control and phytotoxicity.

The aim of this study was to determine if emulsions of anhydrous milk fat (AMF) and soybean oil (SBO), which had been formulated to overcome some of the problems typically associated with the raw ingredients, were effective against powdery mildew on apple seedlings, and to establish if there were any plant health and growth issues associated with regular applications.

\section{MATERIALS AND METHODS}

Two successive experiments were carried out on 'Royal Gala' apple seedlings sourced from Peter Wood (The New Zealand Institute for Plant \& Food Research Limited (PFR), Havelock North, New Zealand).

\section{Experiment 1}

Individual apple seedlings (3-4 weeks old), with four to five true leaves, were potted into plastic pots ( $10 \mathrm{~cm}$ square $\times 12 \mathrm{~cm}$ high) using Butlers ${ }^{\mathrm{TM}}$ potting mix (Hamilton, New Zealand). These were maintained in a controlled environment (CE) room set at a constant temperature of $20^{\circ} \mathrm{C}$ and 16 $\mathrm{h}$ photoperiod, using 400 watt sodium lamps. Pots were hand-watered with tap water every $2-3$ days. The trial commenced after 4 weeks' growth, when the first signs of natural infection by PM were visible on the leaves (i.e. lesions covered $<1 \%$ of the leaf surface area). Prior to the first treatment application, an assessment of mildew was carried out on each seedling. The pots were assigned such that there was a range of infection levels from 0 to $<1 \%$ PM per leaf within each treatment.

There were five treatments (Table 1) applied weekly over the course of 6 weeks to adaxial and abaxial leaf surfaces until runoff to ensure full coverage. Sprays were applied using a hand pressurised 1 litre pump sprayer. There were eight replicate pots per treatment. Treatments were randomised within each block on a single bench within the CE room, using a complete randomised block design.

Leaf assessments of PM incidence and disease severity were carried out immediately before each spray application and 1 week after the last spray.

Table 1 Treatments applied weekly over 6 weeks to 'Royal Gala' apple seedlings infected naturally with powdery mildew.

\begin{tabular}{lcc}
\hline Treatment & Treatment code & Rate \\
\hline Unsprayed control & Unsprayed & \\
Distilled water - sprayed control & Water & \\
Fungicide - Kumulus ${ }^{\circledR}$ DF (BASF, Germany) & Kumulus & $1 \mathrm{~g} /$ litre \\
Emulsified anhydrous milk fat & AMF & $7 \mathrm{~g} /$ litre \\
(New Zealand Milk Products Ltd, New Zealand) & SBO & $20 \mathrm{ml} /$ litre \\
Emulsified soybean oil (Goodman Fielder, New Zealand) & & \\
\hline
\end{tabular}


Visual assessments were carried out with the aid of leaf area infection diagrams (Figure 1) and a disease rating scale (Table 2) described by Spencer (1977). Although these diagrams were originally designed for cucumber, they easily translated for use on apple leaves, as both plants have simple, broad leaves, with the main difference between them being that the apple leaf shape is wider near the middle, rather than lobed as in the cucumber.

Disease severity ratings scored on every individual leaf were then averaged for each plant. At each assessment date, the number of leaves on each apple seedling was determined, excluding all the fresh unexpanded juvenile leaves, and disease incidence was determined as the percentage of leaves expressing PM out of the total number of leaves on each plant.

At the conclusion of the experiment, a number of harvest parameters were measured. The plants were excised at ground level, the stem height was measured from ground level to the tip of the stem and the stem diameter was measured at the widest point. The above-ground portions of the plants were oven-dried at $80^{\circ} \mathrm{C}$ and dry weights were determined.
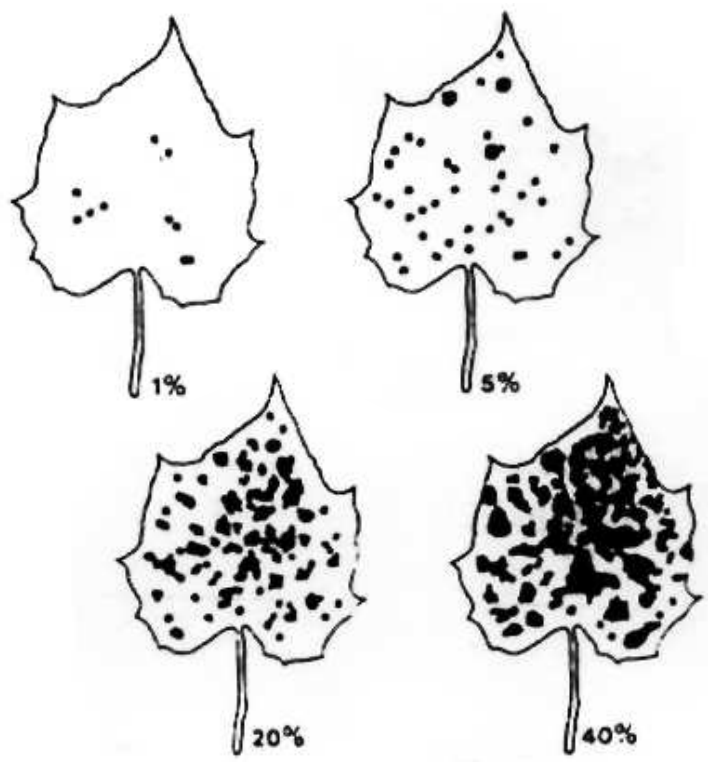

Figure 1 Standard percent leaf area infection diagrams from Spencer (1977) illustrate four levels of powdery mildew infection in cucumber.
Table 2 Powdery mildew disease severity rating scale for leaves (Spencer 1977).

\begin{tabular}{c|c}
\hline $\begin{array}{c}\text { Powdery mildew } \\
\text { disease rating }\end{array}$ & $\begin{array}{c}\text { Percent leaf area } \\
\text { infected }\end{array}$ \\
\hline 0 & No infection \\
1 & $\leq 1 \%$ infection \\
2 & $2-5 \%$ infection \\
3 & $6-20 \%$ infection \\
4 & $21-40 \%$ infection \\
5 & $>40 \%$ infection \\
6 & $100 \%$ infection \\
\hline
\end{tabular}

Data from each PM assessment date were analysed separately. Mean treatment differences were analysed by analysis of variance (ANOVA) using Genstat version 8.1, with means separation by Fisher's least significant difference (LSD) $(\mathrm{P}<0.05)$. The ANOVA was adjusted using the initial disease assessment as a co-variate. Data transformations were not required. Harvest parameters were analysed by ANOVA and LSD $(\mathrm{P}<0.05)$ as described above.

\section{Experiment 2}

The apple seedlings used in the second experiment were 5-6 weeks old, with approximately eight true leaves prior to treatment application. These were potted and maintained as described for the first experiment. At potting the leaves on some plants had the first signs of natural PM infection ( $<1 \%$ of the leaf surface area infected), so the first treatment application was applied on the following day. Treatments were identical to those used in Experiment 1, and were applied at weekly intervals over the course of 7 weeks. Disease assessments, plant health measurements and statistical analysis were carried out as described in Experiment 1.

\section{RESULTS}

\section{Experiment 1}

The mean PM disease severity ratings and PM incidence in the Unsprayed and Water treatments reached maximum levels (a severity rating of 6 , and $100 \%$ incidence) 14 days after the start of the experiment. Both of these treatments were not included in the statistical 
analyses of disease severity and incidence, because the values in the controls had zero standard errors once reaching their maximum levels, and comparisons were not useful as it was clear that the other treatments resulted in lower PM disease severities and incidences.

Throughout the course of the experiment, AMF had the highest disease severity rating $(\leq 20 \%$ mean leaf area infected), followed by Kumulus $(\leq 5 \%$ mean leaf area infected), then SBO $(\leq 1 \%$ mean leaf area infected). Disease severity in the AMF treatment became significantly greater than that in the other two treatments from 20 days after the first spray application (Figure 2). Disease severity increased in all treatments 35 days after the first treatment application (Figure 2).

Figure 3 shows that disease incidence in the AMF treatment was significantly higher than that in the Kumulus and SBO treatments throughout the duration of the experiment, except at the final assessment date, when incidence in the Kumulus and SBO treatments had increased. The SBO treatment resulted in the lowest overall disease incidence, of $\leq 46 \%$ (Figure 3 ).

Overall, shoot dry weights, shoot heights and stem diameters were significantly greater in the Kumulus and AMF treatments than in the Unsprayed and Water controls (Table 3). These growth variables were also higher in the SBO treatment than in the controls, but the difference was not significant (Table 3).

\section{Experiment 2}

As described earlier in Experiment 1, the Unsprayed and Water treatments were not included in the statistical analyses of disease severity and incidence.

Disease severities in the Kumulus and AMF treatments were not significantly different throughout the experiment (Figure 4). The SBO treatment resulted in significantly better control of PM severity than the Kumulus treatment for approximately the first 25 days after the first treatment application, but there was significantly greater PM severity in the SBO treatment than in the Kumulus treatment from day 25 until the termination of the experiment (Figure 4).
Table 3 Shoot dry weight (g), stem height $(\mathrm{cm})$ and stem diameter $(\mathrm{mm})$ measured on the above-ground parts of 'Royal Gala' apple seedlings in Experiment 1 at the conclusion of 6 weeks of weekly spray treatments (Kumulus ${ }^{\circledR}$ DF fungicide, anhydrous milk fat or soybean oil) to control powdery mildew. Control plants were left unsprayed or sprayed with distilled water.

\begin{tabular}{cllc}
\hline Treatment & $\begin{array}{c}\text { Dry } \\
\text { weight }\end{array}$ & Height & $\begin{array}{c}\text { Stem } \\
\text { diameter }\end{array}$ \\
\hline Kumulus & $3.7 \mathrm{a}^{1}$ & $48.9 \mathrm{a}$ & $3.3 \mathrm{a}$ \\
AMF & $3.1 \mathrm{ab}$ & $41.9 \mathrm{ab}$ & $3.1 \mathrm{ab}$ \\
SBO & $2.5 \mathrm{abc}$ & $37.4 \mathrm{abc}$ & $2.8 \mathrm{bc}$ \\
\hline Unsprayed & $1.9 \mathrm{bc}$ & $30.2 \mathrm{bc}$ & $2.5 \mathrm{~cd}$ \\
\hline Water & $1.7 \mathrm{c}$ & $25.4 \mathrm{c}$ & $2.3 \mathrm{~d}$ \\
\hline LSD & 1.2 & 13.3 & 0.5 \\
$(\mathrm{P}=0.05)$ & & & \\
\hline
\end{tabular}

${ }^{1}$ Means followed by the same letters within each column are not significantly different according to Fishers LSD $\mathrm{P}<0.05$ test.

A marked decrease in disease incidence was observed in the SBO treatment in the early stages of Experiment 2, because of the emergence of new leaves that had not become infected (Figure 5). Disease incidence was lower in the SBO treatment than in the Kumulus treatment for the first half of the experiment, but this trend changed 30 days after the first treatment (Figure 5). At the final assessment, PM disease incidence in the Kumulus treatment was significantly lower than in the AMF and SBO treatments (Figure 5).

Overall, apple seedling growth variables were significantly higher in the Kumulus, AMF and SBO treatments than in the Unsprayed and Water controls (Table 4). Variables measured in the AMF and Kumulus treatments were not statistically different from one another (Table 4).

\section{DISCUSSION}

The Kumulus, AMF and SBO treatments significantly reduced powdery mildew severity and incidence in apple seedlings compared with the Water and Unsprayed controls, thereby increasing 

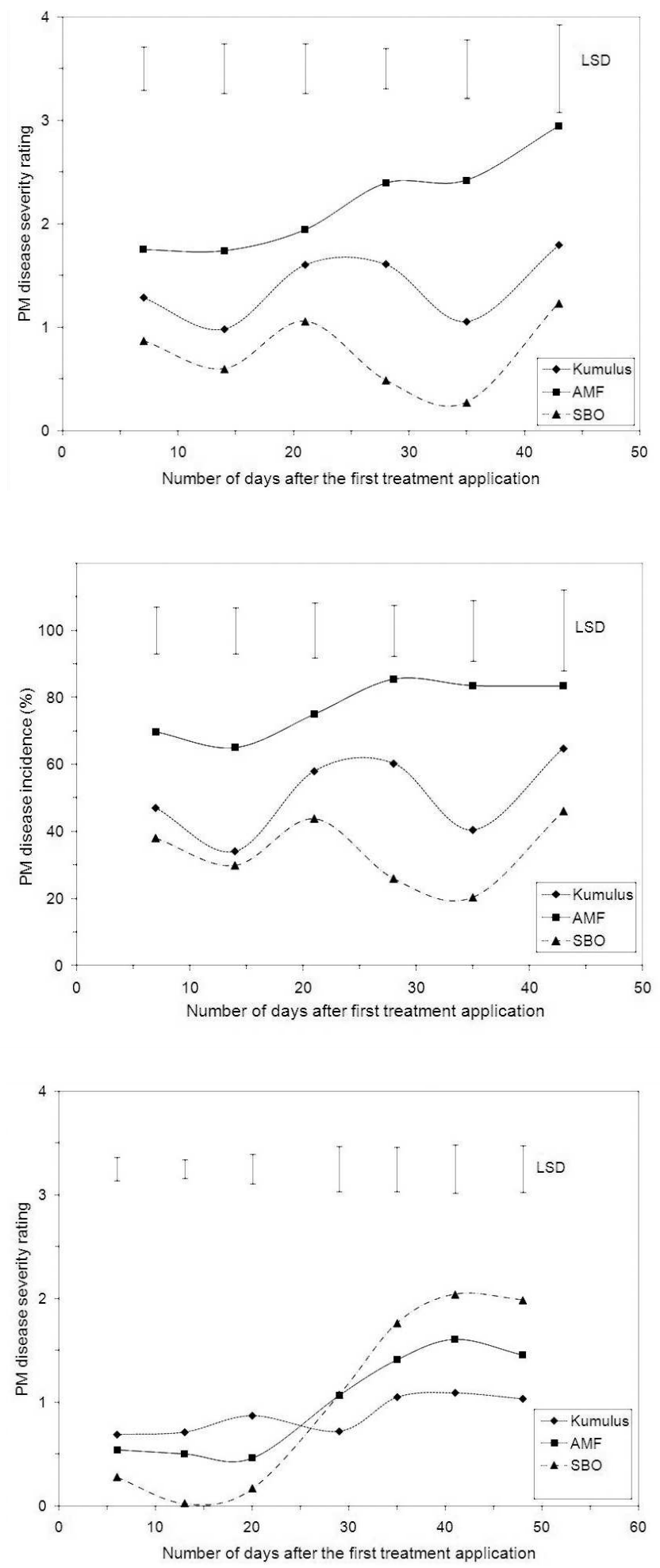

Figure 2 Powdery mildew (PM) disease severity on leaves of 'Royal Gala' apple seedlings in Experiment 1 after weekly treatments for 6 weeks with Kumulus fungicide, anhydrous milk fat (AMF) or soybean oil (SBO). Disease severity is based upon percentage leaf area infected, where: $0=$ no infection; $1=$ $\leq 1 \%$ infection; $2=2-5 \%$ infection; $3=$ $6-20 \%$ infection; $4=21-40 \%$ infection; $5=>40 \%$ infection; and $6=100 \%$ infection. Data from each assessment date were analysed separately, with the least significant difference (LSD, $\mathrm{P}=0.05$ ) error bars providing means separation at each assessment date.

Figure 3 Powdery mildew (PM) disease incidence (\%) on leaves of 'Royal Gala' apple seedlings in Experiment 1 after weekly treatments for 6 weeks with Kumulus fungicide, anhydrous milk fat (AMF) or soybean oil (SBO). Data from each assessment date were analysed separately, with the least significant difference (LSD, $\mathrm{P}=0.05$ ) error bars providing treatment means separation at each assessment date.

Figure 4 Powdery mildew (PM) disease severity on leaves of 'Royal Gala' apple seedlings in Experiment 2 after weekly treatments for 7 weeks with Kumulus fungicide, anhydrous milk fat (AMF) or soybean oil (SBO). Disease severity is based upon percentage leaf area infected, where: $0=$ no infection; $1=$ $\leq 1 \%$ infection; $2=2-5 \%$ infection; $3=$ $6-20 \%$ infection; $4=21-40 \%$ infection; $5=>40 \%$ infection; and $6=100 \%$ infection. Data from each assessment date were analysed separately, with the least significant difference (LSD, $\mathrm{P}=0.05$ ) error bars providing means separation at each assessment date. 


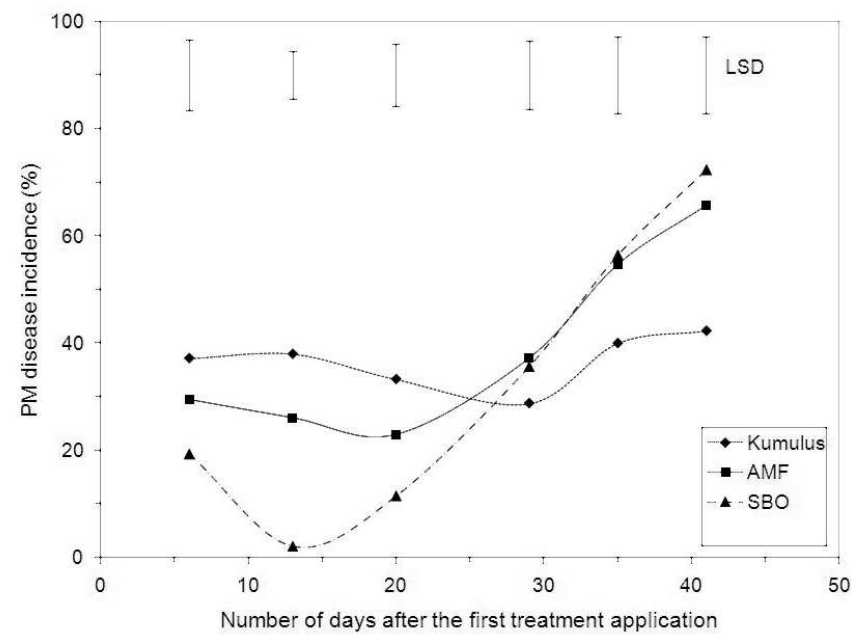

Figure 5 Powdery mildew (PM) disease incidence (\%) on leaves of 'Royal Gala' apple seedlings in Experiment 2 after weekly treatments for 7 weeks with Kumulus fungicide, anhydrous milk fat (AMF) or soybean oil (SBO). Data from each assessment date were analysed separately, with the least significant difference (LSD, $\mathrm{P}=0.05$ ) error bars providing treatment means separation at each assessment date. seedling dry weight, height and stem diameter. The enclosed environment in the CE rooms was very conducive to the pathogen, as evidenced by plants in the control treatments exhibiting the maximum possible PM incidence and severity just 14 days after the start of both experiments. Despite the stringency of the product efficacy test, PM control after AMF and SBO treatment

Table 4 Shoot dry weight $(\mathrm{g})$, stem height $(\mathrm{cm})$ and stem diameter ( $\mathrm{mm}$ ) measured on the aboveground parts of 'Royal Gala' apple seedlings in Experiment 2 at the conclusion of 7 weeks of weekly spray treatments (Kumulus ${ }^{\circledR}$ DF fungicide, anhydrous milk fat or soybean oil) to control powdery mildew. Control plants were left unsprayed or sprayed with distilled water.

\begin{tabular}{llll}
\hline Treatment & $\begin{array}{c}\text { Dry } \\
\text { weight }\end{array}$ & Height & $\begin{array}{c}\text { Stem } \\
\text { diameter }\end{array}$ \\
\hline Kumulus & $2.5 \mathrm{ab}^{1}$ & $27.5 \mathrm{a}$ & $2.8 \mathrm{ab}$ \\
AMF & $2.9 \mathrm{a}$ & $27.9 \mathrm{a}$ & $3.0 \mathrm{a}$ \\
SBO & $2.2 \mathrm{bc}$ & $24.7 \mathrm{a}$ & $2.7 \mathrm{abc}$ \\
\hline Unsprayed & $1.8 \mathrm{c}$ & $14.3 \mathrm{~b}$ & $2.5 \mathrm{bc}$ \\
\hline Water & $1.9 \mathrm{c}$ & $15.1 \mathrm{~b}$ & $2.4 \mathrm{c}$ \\
\hline LSD $(\mathrm{P}=0.05)$ & 0.6 & 8.4 & 0.4 \\
\hline
\end{tabular}

${ }^{1}$ Means followed by the same letters within each column are not significantly different according to Fishers LSD $\mathrm{P}<0.05$ test. was at least as good as, if not better than that after the Kumulus treatment for the first 3-4 weeks of each experiment in the CE rooms. However, the efficacy of these natural product-based treatments relative to Kumulus ${ }^{\circledR}$ DF fungicide was reduced under conditions of high disease pressure, up to 5 weeks after the first treatment application. This was especially evident in the second experiment, which ran for a week longer than the first trial. The plants in the second trial were also larger, resulting in a greater surface area of infected material at the start of the experiment.

Kumulus ${ }^{\circledR}$ DF fungicide, AMF and SBO do not have any strong eradicant activity and can only be applied as protectants to prevent new infections of host tissue, and thus disease pressure increased over time. One possible explanation for the better performance of the Kumulus treatment over the long term might be that although Kumulus ${ }^{\circledR}$ DF is not classed as a systemic fungicide, it does have a volatile phase (BASF 2003), which might provide better spray penetration to partially unfolded leaves, whereas AMF and SBO have contact action only. The volatile phase of Kumulus ${ }^{\circledR}$ DF is more effective in an enclosed environment, which makes it particularly suited to use in the CE rooms. Although Kumulus ${ }^{\circledR}$ DF performed well in the indoor experiments, use of sulphur in the field is restricted because it is an irritant that can cause asthma-like reactions and allergies (Faloon 2011), 
and it is phytotoxic if applied at temperatures $>25^{\circ} \mathrm{C}$ (Young 2009). AMF and SBO are alternative products that do not have these problems, but field trials are necessary to determine how these natural product-based treatments perform in a non-controlled environment.

Harvest parameters measured in SBO-treated plants were not as favourable as in the AMF- and Kumulus-treated plants. This is possibly because SBO protection was less durable than that of AMF under high disease pressure, providing less protection against leaf damage by the pathogen and resulting in a greater depletion of photosynthetic area.

Use of fats and oils represents a durable disease control option because oils have multiple modes of action and low potential for resistance development compared with DMI fungicides, which disrupt sterol synthesis at a single biochemical site and have high resistance potential (Adaskaveg et al. 2010). The need to develop alternative sources of control is particularly important given the breakdown of an important powdery resistance gene in apple (Caffier \& Parisi 2007).

This study represents the first report of AMF being used to control powdery mildew, and the first report of the use of SBO against apple PM since 1993 (Northover \& Schneider 1993). Savocchia et al. (2011) evaluated milk and botanical oils for control of grapevine powdery mildew, but data from three seasons showed that these products provided relatively poor disease control on Chardonnay grapes. Although SBO has been used in trials to control PM in other crops, results have been variable (Northover \& Schneider 1996; Jee et al. 2009), probably because of differences in formulation. The present results indicate that the AMF and SBO formulations used in this research offer new alternatives for use in integrated disease control programmes, for control of powdery mildew in apple nurseries, and in organic programmes. Further field investigations of the effects of these AMF and SBO formulations on powdery mildew infections of apple blossoms and fruit are warranted.

\section{ACKNOWLEDGEMENTS}

Special thanks to Fonterra (formerly New Zealand Milk Products Ltd) for contributing funding to this research programme, which has lead to a provisional patent (PCT/ NZ2005/000167; WO 2006/006878 A1); Peter Wood (PFR) for supplying the apple seedlings used in this research; and John Waller (AgResearch, Hamilton, New Zealand) for statistical analysis.

\section{REFERENCES}

Adaskaveg J, Gluber D, Michailides T, Holtz B 2010. Efficacy and timing of fungicides, bactericides, and biological for deciduous tree fruit, nut, strawberry, and vine crops. http:// scholarship.org/uc/item/61n96422 (accessed 6 April 2011).

Agrios GN 1997. Plant pathology. Academic Press, New York, USA. Fourth edition. 635 p. Bettiol W 1999. Effectiveness of cow's milk against zucchini squash powdery mildew (Sphaerotheca fuliginea) in greenhouse conditions. Crop Protection 18: 489-492.

BioGro 2011. Directory of Biogro certified inputs for producers. http://www.biogro.co.nz/ directory-crop.pdf (accessed 6 April 2011).

BSAF 2003. Kumulus ${ }^{\oplus}$ DF fungicide label information. http://www.agro.basf.co.nz/ label/basfnz/KUMULUS_DF_13101558.pdf (accessed 1 April 2011).

Caffier V, Parisi L 2007. Development of apple powdery mildew on sources of resistance to Podosphaera leucotricha, exposed to an inoculum virulent against the major resistance gene P1-2. Plant Breeding 126(3): 319-322.

Creemers P, Vanmechelen A 1999. Managing fungal disease on pome fruits in relation with ant-resistance strategies for modern fungicides. Modern Fungicides and Antifungal Compounds II: 257-266.

Creemers P, Van Laer S, Van Mechelen A, Vorstermans B, Hauake K 2007. Evaluation of the users value of slats against apple scab and powdery mildew for the integrated fruit production. Communications in Agricultural and Applied Biological Sciences 72(4): 917-923. 
Crisp P, Bruer D 2001. Organic control of powdery mildew without sulfur. Australian Grapegrower and Winemaker 452: 22.

Faloon S. 2011. The symptoms of a sulphur allergy. eHow ${ }^{\mathrm{TM}}$ Health. http://www.ehow. com/about_5048091_symptoms-sulphurallergy.htm (accessed 7 April 2011).

Gao LQ, Berrie A, Yang JR, Xu XM 2009. Within- and between-orchard variability in the sensitivity of Venturia inaequalis to myclobutanil, a DMI fungicide, in the UK. Pest Management Science 65(11): 1241-1249. Jee HJ, Shim CK, Ryu KY, Park JH, Lee BM, Choi DH, Ryu GH 2009. Control of powdery and downy mildews of cucumber by using cooking oils and yolk mixture. Plant Pathology Journal 25(3): 280-285.

Kabara J 1978. Fatty acids and derivatives as antimicrobial agents - a review. American Oil Chemists' Society Monograph 5: 1-14.

Kabara J 1984. Antimicrobial agents derived from fatty acids. Journal of the American Oil Chemists' Society 61: 397-403.

Ko WH, Wang SY, Hsieh TF, Ann PJ 2003. Effects of sunflower oil on tomato powdery mildew caused by Oidium neolycopersici. Journal of Phytopathology 151(3): 144-148.

Kumar J, Chaube HS, Sing US, Mukhopadhyay AN 1992. Plant diseases of international importance. Volume III. Diseases of fruit crops. Prentice Hall, Englewood Cliffs, USA. $456 \mathrm{p}$.
Northover J, Schneider KE 1993. Activity of plant oils on diseases caused by Podosphaera leucotricha, Venturia inaequalis, and Albugo occidentalis. Plant Disease 77(2): 152-157.

Northover J, Schneider KE 1996. Physical modes of action of petroleum and plant oils on powdery and downy mildews of grapevines. Plant Disease 80(5): 544-550.

Savocchia S, Mandel R, Crisp P, Scott ES 2011. Evaluation of 'alterative' materials to sulphur and synthetic fungicides for control of grapevine powdery mildew in a warm climate region of Australia. Australasian Plant Pathology 40(1): 20-27.

Spencer DM 1977. Standardized methods for the evaluation of fungicides to control cucumber powdery mildew. In: McFarlane NR ed. Crop protection agents - their biological evaluation. Academic Press, London. Pp. 455-464.

Yoder KS 1992. Powdery mildew of apple. In: KumarJ, ChaubeHS, Sing US, Mukhopadhyay AN ed. Plant diseases of international importance. Volume III. Diseases of fruit crops. Prentice Hall, Englewood Cliffs, USA. Pp. 66-89.

Young S. 2009. New Zealand Novachem agrichemical manual. AgriMedia Ltd, Christchurch, New Zealand. 779 p. 